RESEARCH REPORT

\title{
Relation between early life socioeconomic position and all cause mortality in two generations. A longitudinal study of Danish men born in 1953 and their parents
}

\author{
Merete Osler, Anne-Marie Nybo Andersen, G David Batty, Bjørn Holstein
}

J Epidemiol Community Health 2005;59:38-41. doi: 10.1136/jech.2004.020990

\begin{abstract}
Objective: To examine (1) the relation between parental socioeconomic position and all cause mortality in two generations, (2) the relative importance of mother's educational status and father's occupational status on offspring mortality, and (3) the effect of factors in the family environment on these relations.

Design: A longitudinal study with record linkage to the Civil Registration System. The data were analysed using Cox regression models.

Setting: Copenhagen, Denmark.

Subjects: 2890 men born in 1953, whose mothers were interviewed regarding family social background in 1968. The vital status of this population and their parents was ascertained from April 1968 to January 2002.

Main outcome measures: All cause mortality in study participants, their mothers, and fathers.

Results: A similar pattern of relations was found between parental social position and all cause mortality in adult life in the three triads of father, mother, and offspring constituted of the cohort of men born in 1953, their parents, and grandparents. The educational status of mothers showed no independent effect on total mortality when father's occupational social class was included in the model in either of the triads. Low material wealth was the indicator that remained significantly associated with adult all cause mortality in a model also including parental social position and the intellectual climate of the family in 1968. In the men born in 1953 the influence of material wealth was strongest for deaths later in adult life.

Conclusion: Father's occupational social class is associated with adult mortality in all members of the mother-father-offspring triad. Material wealth seems to be an explanatory factor for this association.
\end{abstract}

See end of article for authors' affiliations

Correspondence to:
Dr M Osler Department of

Social Medicine, Institute

of Public Health, University

of Copenhagen,

Blegdamsvej 3, $2200 \mathrm{~N}$

Denmark; M.Osler@

pubhealth.ku.dk

Accepted for publication 20 April 2004

A number of studies have reported an inverse relation between socioeconomic position in childhood and mortality in adult life, ${ }^{1-8}$ an association that generally persists after adjustment for socioeconomic position in adulthood..$^{1-6}$ It has been suggested that the effects on adult mortality of social circumstances in early life are mediated by predisposition to poor health, clustering of certain family patterned behaviours such as smoking and alcohol consumption, and unfavourable material conditions leading to poor housing and unhealthy jobs. ${ }^{9}$ However, the life courses of people growing up poor in 1920s and those growing up poor a generation later differ in relation to education, behaviour (diet, smoking, physical activity), material conditions (housing), and health services. Therefore, it is not just time in regard to a person's lifespan, but also historical time that can influence patterns of health inequalities. ${ }^{10}$ We are not aware of studies that have examined the relation between comparable indicators of childhood social circumstances and adult mortality across two generations, which could elucidate whether this association depends on specific social conditions present at a certain time or place. Thus, in this study, we examine the contribution of the same two indicators of socioeconomic position (father's occupation and mother's education) measured in two generations to the risk of premature death in a cohort of Danish men born in 1953 and their adult parents. Father's occupational class is in general regarded as a marker of the family member's position in the social structure of the society. In the 1950s and earlier it was mainly the mother of the family who raised the children. Consequently, mother's educational status should reflect individual attributes associated with the knowledge and norms of the family. In this study, we also examine whether the relations between socioeconomic position and mortality are influenced by factors reflecting the material wealth and intellectual climate of the family.

\section{METHODS}

According to official statistics, 12270 boys were born within the metropolitan area of Copenhagen during 1953. These persons formed the population of a Danish longitudinal study (Project Metropolit) that has been described in detail elsewhere. ${ }^{11}{ }^{12}$ In brief, the study was started in 1965, when data on perinatal conditions from birth registers and certificates were traced by manual means for each study participant. A total of 11376 of this population, who were alive and living in Denmark in 1968 were registered when the Civil Registration System (CRS) was established. During the same year, cohort members participated in a school based survey that included a questionnaire on social and individual characteristics and tests of cognition. Of them 7877 (62.2\%) participated in the school survey (fig 1). In 1968 a random one in four sample of this birth cohort was drawn. In addition, the highest scoring $10 \%$ and the lowest scoring $10 \%$ on the 1965 cognition test were included in this sample. Trained research staff visited families of study participants for interviews with the mother/carer. A total of $82 \%$ of the invited mothers/carers were interviewed and provided information on their mother's and her husband's educational attainment, occupation, the level of social interaction within the family, and mother's educational aspirations for the child. These data were available for 2890 (25.3\%) of the cohort members. To assess if subjects included in the family survey were representative of the total cohort, we compared their information from birth registers with those who were 
not included. Differences were small. Those who did not participate in the survey had slightly lower mean birth weight ( 3370 versus $3400 \mathrm{~g}$ ) compared with the participants, were more likely to be born to single mothers ( 9.0 versus $6.9 \%$ ), and had higher proportions of fathers with unknown occupations ( 11.8 versus $7.4 \%) .{ }^{11}$

\section{Follow up}

In the spring of 2002 study members and their parents were traced in the Danish CRS, which provided information on vital status from April 1968 to January 2002. All 2890 cohort members were followed up for vital status, and of these, 224 cohort members had died between 1968 and 2002. We also succeeded in tracing the identity and vital status of 2039 mothers and 1825 fathers in the CRS. Of them, 698 mothers and 1057 fathers had died. Deletion of links between parents and their children when they left home or had offspring themselves was a routine procedure in the CRS in the time period between 1968 and 1978, and this accounted for the high proportion of missing information on parental vital status. Mothers with missing information on vital status were more likely to have fathers from working class $(49.4 \%$ versus $41.3 \%$ ) and mothers with a basic education $(88.5 \%$ versus $84.6 \%$ ) compared with those with information on vital status. For fathers, those without information on vital status differed from those remaining in that they had missing information on fathers social class $(23.4 \%$ versus $4.5 \%)$ or mother's educational status $(27.5 \%$ versus $9.0 \%)$ at the survey in 1968.

\section{Measures of socioeconomic position}

From the family interview in 1968 we used the information from the mother about her father's, her husband's, and his father's occupational class. This information was coded by the interviewers into 23 strata (non-urban self employed (four strata); urban self employed (six strata); white collar workers (five strata); blue collar workers (five strata); pensioner; student and unknown. In the preliminary data analyses we computed mortality risk estimates for various combinations of the 23 strata. This exercise suggested that they could be combined into three categories (high/middle, which includes self employed and salaried employed; working class, which included skilled and unskilled workers; unknown, which also included the small groups of pensioners and students). We also

Source population:

All 12270 boys born in Copenhagen area in 1953

Information available:

11376 alive and living in Denmark in 1968 (total cohort)

School survey with cognitive testing in 1965 :

7899 participated

Family survey in 1968

2890 participated: $10 \%$ highest $I Q(n=526)$;

$10 \%$ lowest $I Q(n=448)$; random sample $(n=1916)$

Follow up of family survey

$\begin{array}{ll}\text { Central Person Register in } 2002 \text { for parents and vital status: } \\ \text { Total number traced: } & \text { Dead: } \\ 2890 \text { sub-cohort members } & n=224 \\ 2639 \text { mothers } & n=698 \\ 1825 \text { fathers } & n=1057\end{array}$

Figure 1 Project Metropolit: year of data collection and population for which the data have been collected. used the information on the mother's own and her mother's and mother in law's school education. For each family member this information was reported in nine categories (ranging from seven years of basic school without examination to high school examination). After an evaluation of the risk estimates for each strata were collapsed into two: (1) basic school only ( $<9$ years) with no achievement of final certificate, and (2) secondary or high school certificate.

\section{Other variables}

During the interview with the mothers in 1968, information on the family's material standard of living and the intellectual climate within the family were calculated. We calculated a measure of material wealth counting the number of positive answers to questions on whether the family had: (1) owner occupied accommodation, (2) their own car, and (3) summer cottage or second house in the countryside (the measure of material wealth ranged from 0 (none) to 3 (all)). We also created an indicator of the intellectual climate in which the child was brought up. This was based on whether the interviewed parent read newspapers daily $(1=$ yes; $0=$ no $)$, had read a book within the past month $(1=$ yes; $0=$ no), and how many books there were in the home $(0=$ less than 100 books; $1=$ around 100 books; $2=$ around 300 books; and $3=$ over 1000 books). Thus the indicator of intellectual climate ranged from 0 (not reading books and few books in the home) to 5 (reading books and many books in the home).

\section{Statistical methods}

Associations between early life socioeconomic position (father's occupation and mother's education) and mortality for cohort members and their parents, respectively, were analysed using Cox's proportional hazards regression models. Age was used as the underlying time scale and entry time was age in 1968. Follow up ended at the age of death, migration, or 22 January 2002, whichever came first. Cohort member's age during follow up ranged from 15 to 49 years, while parents' age ranged from 38 to 99 years. The indicators of material wealth and intellectual climate were both associated with mortality in a linear fashion and were thus analysed as continuous variables. We tested the proportional hazard assumption in two different ways: the standard graphical check based on the log of the cumulative hazard and through a formal test of proportionality based on Schoenfeld residuals. This showed a violation of the proportional hazard assumption in the models for the men born in 1953 with respect to the measure of material wealth (the effect was not constant over time/age), which was then treated in stratified models and models that allowed age to interact with material wealth. All statistical analyses were performed using Stata version 7.

\section{RESULTS}

Table 1 shows unadjusted and adjusted hazard ratios (HR) for all cause mortality according to the different socioeconomic indicators for cohort members, their fathers, and their mothers. Men born in 1953 with fathers from working/ unknown class or whose mothers had a basic education in 1968 had higher mortality in adult life compared with those with fathers from high/middle class or mothers with a secondary education, respectively. The estimate for mother's education was attenuated when father's social class was included in the model. Low material wealth and intellectual climate during childhood were also associated with increased adult mortality in the 1953 birth cohort. However, the effect of material wealth on mortality increased with age. Thus the association was lowest for the early deaths before age 35 years ( 100 deaths) HR 1.24 (0.99 to 1.55) and highest for the later deaths (age 35-49 years) HR 1.48 (1.20 to 1.82). When 
Table 1 Hazard ratios (95\% confidence intervals) for the relation of parental socioeconomic position (as reported in 1968) and all cause mortality (followed up from 1968 to 2002) in cohort members (men born in 1953), cohort member's mothers, and cohort member's fathers

\begin{tabular}{|c|c|c|c|c|c|c|}
\hline & $\begin{array}{l}\text { Total number/ } \\
\text { deaths }\end{array}$ & Crude hazard ratio & $\begin{array}{l}\text { Adjusted* hazard } \\
\text { ratio }\end{array}$ & $\begin{array}{l}\text { Adjusted* hazard } \\
\text { ratio }\end{array}$ & $\begin{array}{l}\text { Adjusted* hazard } \\
\text { ratio }\end{array}$ & $\begin{array}{l}\text { Adjusted* hazard } \\
\text { ratio }\end{array}$ \\
\hline \multicolumn{7}{|c|}{$\begin{array}{l}\text { Cohort members (men born in } \\
1953 \text { ) }\end{array}$} \\
\hline \multicolumn{7}{|l|}{ Paternal social class } \\
\hline High/middle class & $1552 / 93$ & 1 & 1 & 1 & 1 & 1 \\
\hline Working class & $987 / 91$ & $1.51(1.14$ to 2.03$)$ & $1.42(1.05$ to 1.93$)$ & $1.25(0.91$ to 1.72$)$ & $1.34(0.99$ to 1.84$)$ & $1.20(0.87$ to 1.66$)$ \\
\hline Unknown & $351 / 40$ & $1.94(1.34$ to 2.81$)$ & $1.89(1.29$ to 2.74$)$ & $1.48(0.98$ to 2.29$)$ & $1.76(1.20$ to 2.60$)$ & $1.42(0.94$ to 2.17$)$ \\
\hline \multicolumn{7}{|c|}{ 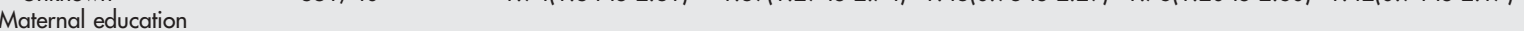 } \\
\hline Secondary & $1226 / 79$ & 1 & 1 & 1 & 1 & 1 \\
\hline Basic & $1657 / 145$ & $1.35(1.02$ to 1.78$)$ & $1.20(0.90$ to 1.60$)$ & $1.14(0.86$ to 1.33$)$ & $1.10(0.81$ to 1.50$)$ & $1.08(0.79$ to 1.47$)$ \\
\hline Unknown & $7 / 0$ & - & - & - & - & - \\
\hline \multicolumn{7}{|l|}{ Childhood } \\
\hline Material wealth $(0-3) \dagger$ & & $1.24(0.99$ to 1.55$) \S$ & & $1.13(0.88$ to 1.46$) \S$ & & $1.02(0.87$ to 1.45$) \S$ \\
\hline Material wealth $(0-3) \dagger$ & & $1.43(1.20 \text { to } 1.82)^{\circ}$ & & $1.34(1.06 \text { to } 1.69)^{\circ}$ & & $1.32(1.04$ to 1.97$)$ \\
\hline Intellectual climate $(0-5) \ddagger$ & & $1.16(1.05$ to 1.28$)$ & & & $1.09(0.97$ to 1.22$)$ & $1.06(0.95$ to 1.20$)$ \\
\hline \multicolumn{7}{|l|}{ Mothers of cohort members } \\
\hline \multicolumn{7}{|l|}{ Paternal social class } \\
\hline High/middle class & $1149 / 374$ & 1 & 1 & 1 & 1 & 1 \\
\hline Working class & $841 / 306$ & $1.35(1.16$ to 1.57$)$ & $1.31(1.13$ to 1.53$)$ & $1.23(1.05$ to 1.44$)$ & $1.22(1.04$ to 1.43$)$ & $1.17(0.99$ to 1.37$)$ \\
\hline Unknown & $49 / 18$ & $1.46(0.91$ to 2.35$)$ & $1.48(0.91$ to 2.38$)$ & $1.36(0.84$ to 2.19$)$ & $1.46(0.90$ to 2.34$)$ & $1.34(0.83$ to 2.16$)$ \\
\hline \multicolumn{7}{|c|}{ 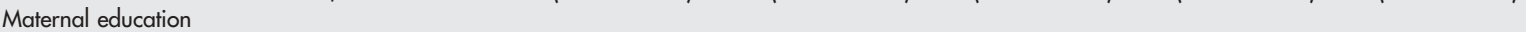 } \\
\hline Secondary & $220 / 58$ & 1 & 1 & 1 & 1 & 1 \\
\hline Basic & $1724 / 605$ & $1.34(1.03$ to 1.76$)$ & $1.20(0.94$ to 1.63$)$ & $1.15(0.70$ to 1.64$)$ & $1.06(0.80$ to 1.41$)$ & $1.03(0.77$ to 1.37$)$ \\
\hline Unknown & $95 / 35$ & $1.21(0.79$ to 1.84$)$ & $1.15(0.76$ to 1.76$)$ & $1.07(0.70$ to 1.64$)$ & $1.01(0.66$ to 1.41$)$ & $0.97(0.63$ to 1.49$)$ \\
\hline \multicolumn{7}{|c|}{ 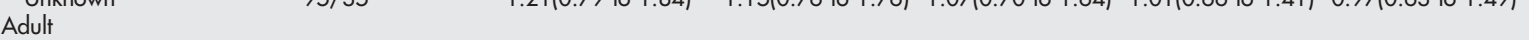 } \\
\hline Material wealth (0-3)† & & $1.25(1.15$ to 1.36$)$ & & $1.21(1.11$ to 1.32$)$ & & $1.16(1.07$ to 1.28$)$ \\
\hline Intellectual climate $(0-5) \ddagger$ & & $1.35(1.09$ to 1.22$)$ & & & $1.13(1.06$ to 1.20$)$ & $1.10(1.03$ to 1.17$)$ \\
\hline \multicolumn{7}{|l|}{ Fathers of cohort members } \\
\hline \multicolumn{7}{|l|}{ Paternal social class } \\
\hline High/middle class & $1037 / 593$ & 1 & 1 & 1 & 1 & \\
\hline Working class & $706 / 414$ & $1.18(1.04$ to 1.35$)$ & $1.18(1.04$ to 1.34$)$ & $1.08(0.94$ to 1.24$)$ & $1.13(0.99$ to 1.28$)$ & $1.06(0.93$ to 1.21$)$ \\
\hline Unknown & $82 / 52$ & $1.45(1.09$ to 1.92$)$ & $1.36(1.01$ to 1.83$)$ & $1.19(0.88$ to 1.62$)$ & $1.28(0.95$ to 1.73$)$ & $1.16(0.86$ to 1.57$)$ \\
\hline \multicolumn{7}{|c|}{ 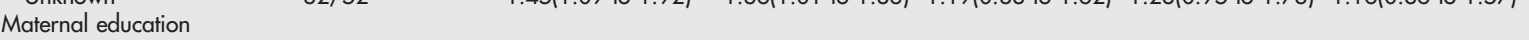 } \\
\hline Secondary & $153 / 77$ & 1 & 1 & 1 & 1 & 1 \\
\hline Basic & $1508 / 872$ & $1.23(0.97$ to 1.56$)$ & $1.15(0.90$ to 1.46$)$ & $1.06(0.84$ to 1.35$)$ & $1.00(0.79$ to 1.29$)$ & $0.97(0.76$ to 1.24$)$ \\
\hline \multirow{2}{*}{\multicolumn{7}{|c|}{ 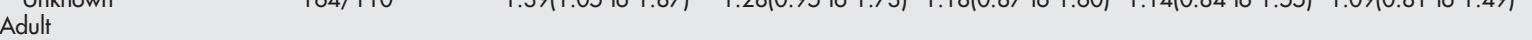 }} \\
\hline & & & & & & \\
\hline Material wealth $(0-3) \dagger$ & & $1.26(1.18$ to 1.34$)$ & & $1.24(1.15$ to 1.33$)$ & & $1.20(1.12$ to 1.29$)$ \\
\hline Intellectual climate $(0-5) \ddagger$ & & $1.12(1.08$ to 1.18$)$ & & & $1.27(0.94$ to 1.72$)$ & $1.08(1.03$ to 1.14$)$ \\
\hline
\end{tabular}

the material wealth and/or intellectual climate were entered into the model the measure of material wealth was the only variable significantly associated with increased mortality later in life. Inclusion of the parent's total lifespan (less than 65 years versus 65 years or more) attenuated the risk estimates only marginally (data not shown).

Among cohort member's parents, mortality rates were associated with their father's occupational social class and mother's educational status. The pattern of these associations was similar to that seen for their adult son. The measures of material wealth and intellectual climate, which in these analyses represented parental adult environment, were likewise inversely associated with mortality in both mothers and fathers (table 1). All analyses were repeated for the 1916

\section{Key points}

- Father's occupational social class is associated with adult mortality in sons, fathers, and mothers.

- In men born in 1953 the association between father's social class and adult mortality seems to be partially mediated through measures of material wealth in childhood rather than the intellectual climate in which the child was raised. men from the random sample (fig 1). This approach gave essentially the same results as those based on all participants in the family survey.

\section{DISCUSSION}

In this study we found a similar pattern of relation between parental social position and all cause mortality across two generations, namely for a cohort of men born in 1953 and for their parents. In mothers, fathers, and sons the educational status of their respective mothers showed no independent effect on total mortality when paternal occupational status was included in the model. Low material wealth was the indicator that remained significantly associated with adult all cause mortality in a model, also including father's social class, mother's education, and the intellectual climate of the family in 1968.

\section{Policy implications}

- Material wealth of the family seems to be one of the mechanisms mediating the association between childhood socioeconomic position and health in later life.

- This emphasises the importance of prevention strategies aimed at improving the living conditions of socioeconomically disadvantaged families. 
In this study there was nearly complete follow up for study participants and there were only minor differences in early life characteristics between those who attended and those who did not attend the family survey. Thus, the conclusions might apply to all members of this 1953 male birth cohort. Follow up was less successful for the parents among whom about one third could not be traced, but we found only minor differences in baseline variables between parents followed up on those who could not be traced. Losses to follow up, therefore, are unlikely to result in bias. The study allows us to examine the same indicators of socioeconomic position across two generations. However, the data on cohort member's parent's and grandparent's occupation and education were based on mother's report in 1968. This information seems to be less complete for paternal grandparents as the numbers of unknown were higher. However, the occurrence of these missing data is most likely to be random and it did not seem to influence the risk estimates as they were comparable for mothers and fathers. In addition, the information on material wealth and intellectual environment covers the same period and thus reflect the adult circumstances for parents and childhood circumstances for their son. This is a limitation in the models that have parental mortality as outcome because the pathway hypothesised is: parental socioeconomic position-material wealth and intellectual climate in which the child was brought up-adult mortality. Although we could study the influence of material wealth on adult mortality we had no information on behavioural factors such as smoking and alcohol consumption, which might also cluster within families. Our study is also based on a limited number of cases, which does not allow us to study specific causes of deaths. On the other hand, we split the survival analyses into early and later deaths as age at death may be a proxy for external causes of deaths in young ages and chronic diseases in older ages. There was an overrepresentation of subjects with low or high IQ in our study. However, we do not find that this selection will bias our analyses because IQ did not modify the effect of father's occupational social class on mortality. ${ }^{12}$ Furthermore, analyses stratified into subsamples (10\% highest IQ, 10\% lowest IQ; and the random sample) showed the same direction of associations.

Although the actual composition of socioeconomic groups as well as social differences in behaviours and material conditions change over time, the association between socioeconomic position in early life and mortality has been found in studies including prewar or postwar birth cohorts. ${ }^{1-6}$ This was also apparent in this study that covers two generations and it could be taken as support for a biological mechanisms linked to families' health. On the other hand, the fact that the inclusion of parental lifespan in the model only slightly reduced the relation between social circumstances early in life and offspring mortality does not lend support for this mechanistic pathway. The choice of conceptualisation and measurement of socioeconomic position influences our thinking about pathways between social conditions and health. ${ }^{13}$ The measurement of socioeconomic position by education stimulates the identification of pathways within the person, such as knowledge. The measurement of occupational social class may stimulate the identification of pathways linked to the social structure, while measurements of material wealth identify pathways related to the materialistic explanation. Most previous studies on childhood social circumstances and mortality have found clear associations between father's occupational social class and offspring mortality later in life. ${ }^{1-8} \mathrm{~A}$ few studies, however, have shown weaker relations between parental educational status and offspring mortality. ${ }^{35}$ Furthermore, studies have found that housing quality or car ownership measured in childhood influence mortality in adult life. ${ }^{45}$ In support for the materialistic pathway, this study showed the most persuasive associations for the indicator of material wealth, although one should be cautious when comparing effects that are comparatively small. The association between material wealth and mortality was clearest in the older age groups where deaths from chronic diseases dominate the causes of deaths. In the 1950s Denmark, poor material wealth was an indicator of suboptimal housing conditions and nutrition that might influence the development of respiratory and coronary diseases later in life and thus further support this pathway. The association of mortality with mother's education was attenuated considerably when the effects of father's occupational status or material score were controlled for. This suggests that an individual pathway linked to education such as knowledge is a less important mechanism for the childhood social circumstances and adult mortality relation. However, it should be noted that we rely on data collected in the past, and some of the variables are crudely measured. This is a problem in analyses where the goal is to contrast different mechanisms.

In conclusion, in this study father's occupational social class is associated with adult mortality in sons, fathers, and mothers. This association seems to be partially mediated via measures of material wealth in childhood rather than individual psychosocial attributes, at least with the measures available here.

\section{ACKNOWLEDGEMENTS}

We thank all those who started and/or continued the study from 1965 to 1983: K Svalastoga, E Høgh, P Wolf, T Rishøj, G StrandeSørensen, E Manniche, B Holten, IA Weibull, and A Ortmann for their thorough work on the project.

\section{CONTRIBUTORS}

MO and AMNA had the original idea for the study. MO conducted the data analyses and wrote the first version of the paper. All authors took part in the discussion and revision of the paper. MO is guarantor.

\section{Authors' affiliations}

M Osler, A-M N Andersen, G D Batty, B Holstein, Department of Social Medicine, Institute of Public Health, University of Copenhagen, Denmark

Funding: Danish Heart Association; the Lundbeck foundation; the Danish Health Insurrance Funds.

Conflicts of interests: none declared.

\section{REFERENCES}

1 Nystrom Peck M. The importance of childhood socio-economic group for adult health. Soc Sci Med 1994:39:553-62.

2 Vagerö D, Leon D. Effect of social class in childhood and adulthood on adult mortality. Lancet 1994;343:1224-5.

3 Pensola TH, Valkonen T. Effect of parental social class, own education and social class on mortality among young men. Eur J Public Health 2002;12:29-36.

4 Davey Smith G, Hart C, Blane D, et al. Lifetime socio-economic position and mortality: prospective observational study. BMJ 1997;314:547-52.

5 Kuh D, Hardy R, Langenberg C, et al. Mortality in adults aged 26-54 years related to socio-economic conditions in childhood and adulthood: postwar birth cohort study. BMJ 2002;325:1076-80.

6 Davey Smith G, Hart C, Blane D, et al. Adverse socio-economic conditions in childhood and cause specific adult mortality: prospective observational study. BMJ 1998;316:1631-5

7 Clausen B, Davey Smith G, Thelle D. Impact of childhood and adulthood socioeconomic position on cause specific mortality: the Oslo mortality study. J Epidemiol Community Health 2003;57:40-5.

8 Lynch J, Kaplan GA, Cohen RD, et al. Childhood and adult socioeconomic status as predictors of mortality in Finland. Lancet 1994;343:524-7.

9 Hertzman C. The biological embedding of early experience and its effects on health in adulthood. Ann N Y Acad Sci 1999;896:85-95.

10 Hertzman C, Power C, Matthews S, et al. Using a framework of society and lifecourse to explain self-rated healht in early adulthood. Soc Sci Med 2001;53:1575-85

11 Osler M, Andersen AMN, Lund R, et al. Revitalising the Metropolit 1953 Danish male birth cohort: Background, aims and design. Paed Perinatal Epidemiol 2004; 18:385-94

12 Osler M, Andersen AMN, Due R, et al. Socioeconomic position in early life, birth weight, childhood cognitive function, and adult mortality. A longitudinal study of Danish men born in 1953. J Epidemiol Community Health 2003;57:681-6.

13 Lynch J, Kaplan G. Socioeconomic position. In: Berkman LF, Kawachi I, eds. Social epidemiology. Oxford: Oxford University Press, 2000:13-35. 